\title{
The RND1 Small GTPase: Main Functions and Emerging Role in Oncogenesis
}

\author{
Laetitia Mouly ${ }^{1,2}$, Julia Gilhodes ${ }^{3}$, Anthony Lemarié ${ }^{1,2} \mathbb{E}$, Elizabeth Cohen-Jonathan Moyal 1,2,3, \\ Christine Toulas ${ }^{1,3}$, Gilles Favre ${ }^{1,2,3}$, Olivier Sordet ${ }^{1}$ and Sylvie Monferran ${ }^{1,2, *,+}$ \\ Cancer Research Center of Toulouse, INSERM UMR1037, 31037 Toulouse, France \\ Faculty of Pharmacy and Medecine, Université Toulouse III, 31062 Toulouse, France \\ 3 Institut Claudius Regaud, IUCT-O, 31059 Toulouse, France \\ * Correspondence: sylvie.monferran@inserm.fr; Tel.: +33-5-34-60-95-16; Fax: +33-5-34-60-95-05 \\ + Current Address: Sylvie Monferran, StromaLab, UMR1031, 31432 Toulouse, France.
}

Received: 11 June 2019; Accepted: 21 July 2019; Published: 24 July 2019

\begin{abstract}
The Rho GTPase family can be classified into classic and atypical members. Classic members cycle between an inactive Guanosine DiPhosphate -bound state and an active Guanosine TriPhosphate-bound state. Atypical Rho GTPases, such as RND1, are predominantly in an active GTP-bound conformation. The role of classic members in oncogenesis has been the subject of numerous studies, while that of atypical members has been less explored. Besides the roles of RND1 in healthy tissues, recent data suggest that RND1 is involved in oncogenesis and response to cancer therapeutics. Here, we present the current knowledge on RND1 expression, subcellular localization, and functions in healthy tissues. Then, we review data showing that RND1 expression is dysregulated in tumors, the molecular mechanisms involved in this deregulation, and the role of RND1 in oncogenesis. For several aggressive tumors, RND1 presents the features of a tumor suppressor gene. In these tumors, low expression of RND1 is associated with a bad prognosis for the patients. Finally, we highlight that RND1 expression is induced by anticancer agents and modulates their response. Of note, RND1 mRNA levels in tumors could be used as a predictive marker of both patient prognosis and response to anticancer agents.
\end{abstract}

Keywords: Rho GTPase; RND; migration; oncogenesis; response to anticancer agents; prognosis factor

\section{Introduction}

\section{RND1, an Atypical Rho GTPase}

The Rho family of GTPases includes 20 members, which can be classified into classic and atypical members in humans [1,2] (Figure 1). Classic Rho GTPases, such as RHOA, CDC42, and RAC1, act as molecular switches by cycling between an inactive Guanosine DiPhosphate (GDP)-bound state and an active Guanosine TriPhosphate (GTP)-bound state. The GDP/GTP cycle depends on guanine nucleotide exchange factors (GEFs) and GTPase-activating proteins (GAPs). GEFs facilitate the exchange of GDP with GTP while GAPs promote hydrolysis of GTP into GDP by stimulating the intrinsic GTPase activity of Rho. Atypical Rho GTPases are primarily in an active GTP-bound conformation by two main mechanisms [3,4]. RHOU, and probably also RHOV, have a high nucleotide exchange rate and are therefore considered to be mainly GTP-bound [4]. Due to some substitutions in residues critical for GTP hydrolysis, which correspond to Gly14, Ala61, and Gln63 of RHOA, RND proteins are unable to hydrolyze GTP and consequently, are always activated [3]. RND1 (RHO6) belongs to the RND subfamily that also comprises RND2 (RHO7/RHON) and RND3 (RHO8/RHOE) (Figure 1). Human RND members share 52-61\% homology in their primary sequences (Figure 1). RND proteins 
possess the Rho-specific insert domain (Figure 2), which defines the family of Rho GTPases. Although RND1 shares $41 \%$ identity with RHOA protein (Figure 1), RND proteins differ from other Rho GTPases by several features. They contain an extension of 30 amino acids at the C-terminal and RND1 and RND3 proteins possess 8 and 18 additional amino acids, respectively, at the N-terminal [3]. At the $\mathrm{N}$-terminal, RND1 and RND3 (but not RND2) contain a KERRA (Lys-Glu-Arg-Arg-Ala) sequence that mediates their targeting to lipid rafts, and so their localization at the plasma membrane [5]. Concerning post-translational prenylation, unlike the proteins of the RHOA, RAC1, and CDC42 subfamilies (see Figure 1), which are predominantly geranyl-geranylated, RND proteins are farnesylated due to a methionine in the C-terminal CAAX box. The activity of RND proteins is rather dependent on epigenetic, transcriptional, post-transcriptional, and post-translational mechanisms, than on GDP/GTP exchange [6]. Finally, when bound to GTP, both classic and atypical Rho GTPases bind to their effectors and activate signaling pathways that regulate various cellular processes, such as cytoskeleton dynamic, proliferation, and cell migration $[7,8]$.

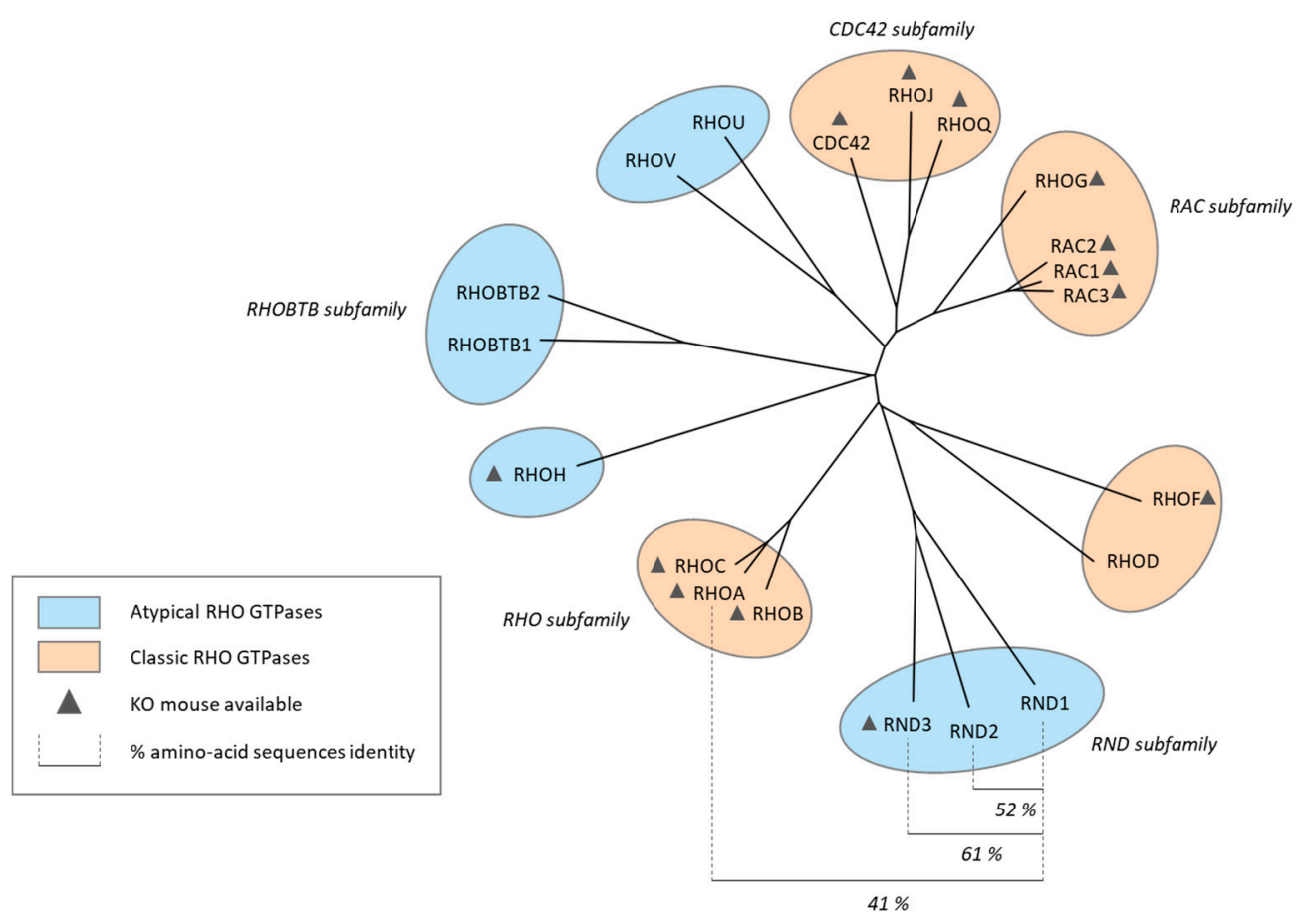

Figure 1. Rho GTPase family. The phylogenetic tree of the Rho GTPase family was obtained from the alignment of the amino-acid sequences of the 20 Rho GTPases using the Clustal Omega program. The tree was generated using the iTOL software. Rho members are structured into eight subfamilies, including the Rho subfamily (RHOA, RHOB, and RHOC), the RAC subfamily (RAC1, RAC2, RAC3, and RHOG), the CDC42 subfamily (CDC42, RHOQ and RHOJ), the RND subfamily (RND1, RND2 and RND3), the RHOU/V family (RHOU and RHOV), the RHOD/F subfamily (RHOD and RHOF), the RHOBTB subfamily (RHOBTB1 and RHOBTB2) and RHOH. Classic Rho GTPases comprise the RHO, RAC, CDC42, and RHOD/F subfamilies. Atypical Rho GTPases include the RND, RHOU/V, RHOBTB, and $\mathrm{RHOH}$ subfamilies. Rho GTPases, which have a knockout $(\mathrm{KO})$ mouse model, are annotated with a triangle. Percentage of amino-acid-sequences identity between RND1 and other Rho GTPases members were determined with the Clustal Omega tool.

Dysregulation of classic Rho GTPases activity can lead to dysregulation of processes important for tumorigenesis, such as metastasis or angiogenesis capacity [9]. Data from the literature suggest that RND1 [10] and RND3 [11,12] play an essential role in oncogenesis and in response to therapeutics. Insofar as these data have been recently well reviewed for RND3 [13], we will focus our discussion on RND1. First, we will review current knowledge on the expression, localization, regulation, 
and functions of RND1 in healthy tissues. Then, we will review its expression in cancers, its role in oncogenesis, and its involvement in the response to anticancer agents.

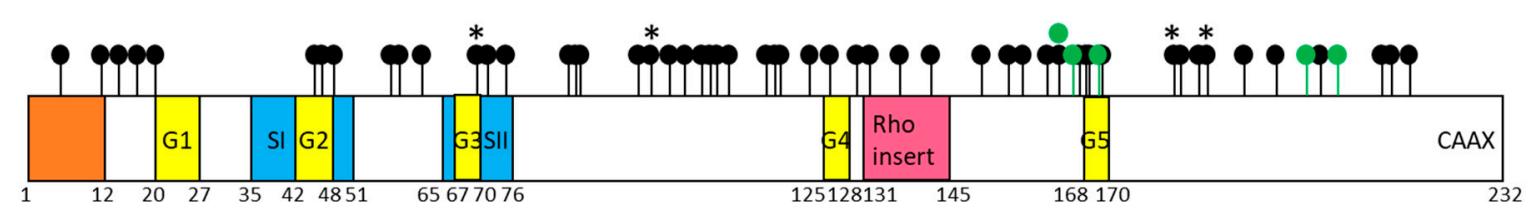

Figure 2. Structure of RND1 gene and mutational pattern in human tumors. The orange box is the lipid raft motif; the yellow boxes are the guanosine nucleotide binding sites; the pink box is Rho insert domain; the blue boxes are the switch domains. SI: Switch I; SII: Switch II. Mutation types and corresponding color codes are as follows: Black represents the missense mutations and green represents the nonsense mutations. The stars indicate the mutations for which the impact on the RND1 function has been studied [10].

\section{RND1 Expression in Healthy Tissues}

Unlike RND3 whose expression is ubiquitous in humans, RND1 is not expressed in all tissues. During embryogenesis, RND1 mRNA is expressed in various human fetal tissues, such as the brain, lungs, liver, and kidneys [3]. In Xenopus, it has been shown that the expression of RND1 varies during the different stages of embryogenesis. RND1 mRNA is particularly expressed during the gastrulation in the ectoderm and the dorsal lip of the blastopore. During neurulation, RND1 mRNA is expressed in the somitogenic mesoderm. At mid-neurula, RND1 transcript is expressed in the somites and in cells forming the neural crest, then decreases after their formation is completed [14].

In adults, human RND1 mRNA is expressed in the liver and several brain tissues and more weakly, in the lungs, pancreas, thymus, prostate, ovaries, and small intestine [3]. In rats, RND1 protein is expressed in the brain, liver, and testis, but not in the muscle [3]. In the rat brain, RND1 protein is strongly expressed in cortical and pyramidal neurons of the hippocampus during synaptic formation [15]. At present the origin of the variation of RND1 expression in tissues is not known. It is conceivable that RND1 may act at very low levels or may control cellular processes specific to particular tissues, such as the brain. It will be described below in the section "Biological Functions of RND1".

During pregnancy, human and rat RND1 mRNA increases in myometrium within the uterus $[16,17]$. In rats, the expression of RND1 mRNA increases until it reaches a maximum value at the end of gestation (21 days). This RND1 mRNA induction depends at least on estradiol and progesterone levels [16]. From the first postpartum day, the expression of RND1 transcript in myometrium immediately falls back to the initial level.

\section{Subcellular Localization of RND1}

\section{Subcellular Localization}

In rats, the endogenous RND1 protein has been detected in the dendrites and the axon of hippocampal neurons [15]. To date, no commercial antibodies have been reported to detect the endogenous human RND1 protein. Thus, to study the subcellular protein localization, transfections of cells with plasmid containing the coding sequence of RND1 were performed. In these models of RND1 overexpression, active RND1 is localized at the plasma membrane $[3,14,18]$ due to its N-terminal extension [5] and its farnesylation [19]. Indeed, deletion of the first seven amino acids of RND1 or treatment with an inhibitor of farnesyl transferase results in a decrease of RND1 at the plasma membrane and its accumulation in the cytoplasm and the nucleus [5,19]. RND1 may be also sequestrated in the cytosol, in a phosphorylated form, when it is bound to 14-3-3 protein [20], which can be considered as an inhibitor of RND1 activity. The kinase that phosphorylates RND1 is unknown (Figure 3). 


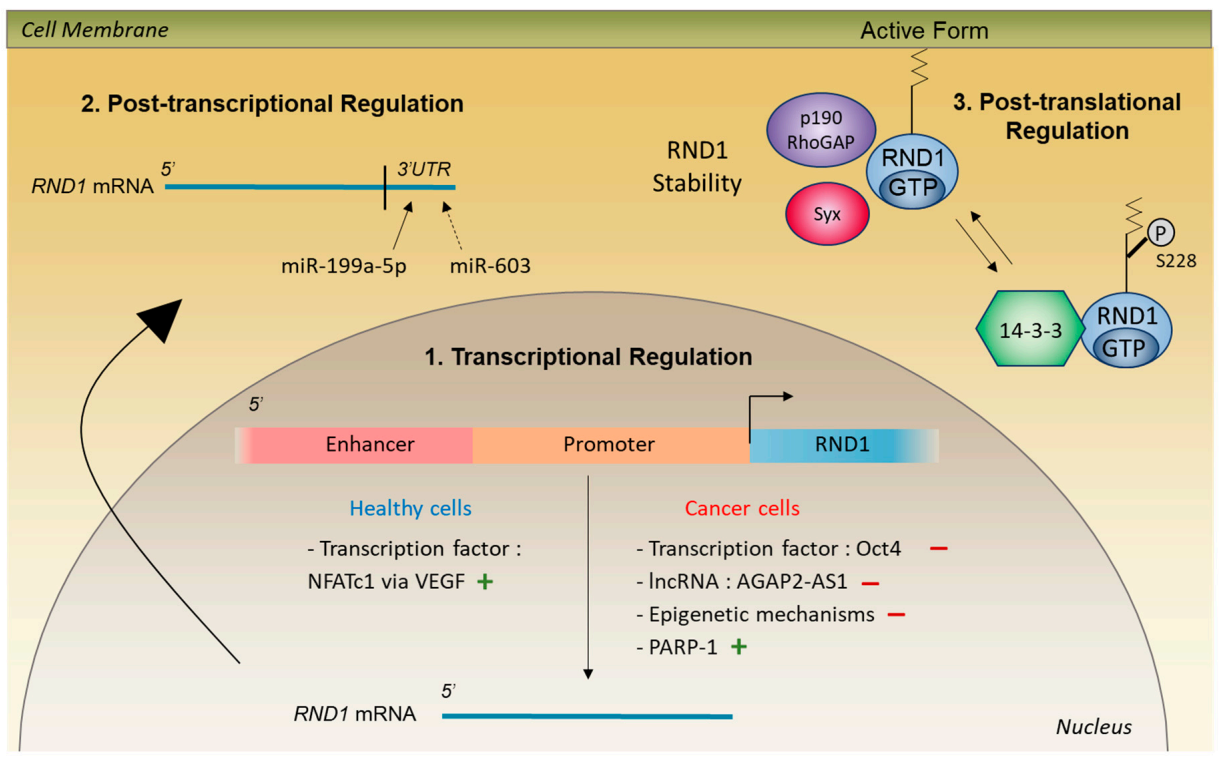

Figure 3. Regulation of RND1 protein in healthy and cancer cells. 1: RND1 transcription is regulated by diverse mechanisms. In healthy cells, the transcription factor NFATc1 increases RND1 transcription (marked as "+" in the figure). In cancer cells, the transcription factor Oct4, the lncRNA AGAP2-AS1 and epigenetic mechanisms, including DNA methylation and histone acetylation, act as repressors of RND1 transcription (marked as "-" in the figure) whereas PARP-1 stimulates RND1 transcription (marked as " + " in the figure). 2: RND1 expression is inhibited by the miRNAs miR-199a-5p and miR-603. The 3'UTR of RND1 mRNA has one or more specific binding sites for miR-199a-5p whereas the binding sites for miR-603 have not yet been identified. 3: RND1 protein is stabilized when it associates with its effectors p190RhoGAP and Syx. When RND1 is phosphorylated, it binds to the 14-3-3 protein, which induces the translocation of RND1 from the plasma membrane to the cytoplasm.

\section{Control of RND1 Expression in Healthy Cells}

Depending on the growth factors, the expression of RND1 can be induced or repressed. RND1 mRNA is decreased by osteoprotegerin in osteoclasts [21] and by various mitogens, such as EGF, insulin, hydrocortisone, or bovine pituitary extracts in mammary MCF-10A epithelial cells [10]. On the contrary, RND1 transcript expression is induced by different growth factors, such as TGF- $\beta$ (transforming growth factor beta) or VEGF (vascular endothelial growth factor) at short times (between $1 \mathrm{~h}$ and $2 \mathrm{~h}$ ) in MCF10A or endothelial cells $[10,22]$. The transcriptional increase of RND1 by VEGF is due to the binding of the NFATc1 (Nuclear Factor of Activated T Cells 1) transcription factor to RND1 promoter and to a distal enhancer region of RND1 gene [22]. Moreover, the expression of RND1 mRNA is also induced by hormones, such as estradiol and progesterone $[16,23]$.

Because RND1 is always in its active GTP-bound form, it is mainly regulated by modifications of its expression. Below are detailed the levels of regulation that have been reported, including transcriptional, post-transcriptional, and post-translational mechanisms, which are summarized in Figure 3.

\subsection{Transcriptional and Post-Transcriptional Regulation}

Concerning the regulation by transcription factors, the binding of the NFATc1 protein to the promoter and to a distal enhancer region of RND1 gene, in response to VEGF, increases the transcription of RND1 in endothelial cells [22]. Regarding the post-transcriptional regulation, overexpression of miR-199a-5p in immortalized urothelial TEU-2 cells results in a decrease of RND1 mRNA [24]. The 3'UTR of RND1 mRNA possesses at least one specific binding site for miR-199a-5p. In addition, overexpression of miR-603 in human cervical cancer HeLa cells and in human embryonic kidney HEK293 cells decreases RND1 mRNA [25]. 


\subsection{Post-Translational Regulation}

Several Rho GTPases are regulated by phosphorylation [26]. When phosphorylation occurs near the CAAX box, it alters the localization and function of Rho GTPases [26]. The binding of the phosphorylated form of RND1 on S228, close to the CAAX box, to 14-3-3 protein induces the translocation of RND1 from the plasma membrane to the cytoplasm and reverses the typical RND1 rounded phenotype described below in the section "Biological Functions of RND1" [20]. The action of 14-3-3 on RND1 is similar to the action of GDIs (GDP-dissociation inhibitors) on classic GTPases. GDIs relocate CDC42 and RHOA from their site of action at the plasma membrane to the cytoplasm in order to prevent interaction with their effectors. The kinase that phosphorylates RND1 is not known. In addition to these phosphorylation processes, the interaction of RND1 with its effectors p190RhoGAP and Syx, a RHOA GEF, increases RND1 stability [27].

\section{Biological Functions of RND1}

\subsection{Regulation of Cell Morphology and Actin Cytoskeleton}

The first cellular effect reported for RND1 (and RND3) is on cell morphology by reducing actomyosin contractibility [3]. These observations are at the origin of the name of the subfamily RND. RND comes from "round" because the overexpression of RND1 or RND3 in fibroblasts results in a rounded cell phenotype [3]. The expression of RND1 induces the loss of stress fibers and focal adhesions helping to anchor the cells to the extracellular matrix. In consequence, cells tend to contract. However, they maintain some contact with the matrix, which gives them a dendritic phenotype [3].

The first mechanism described to explain how RND1 reduces actomyosin contractibility is through RHOA inhibition [28]. RND1 (and RND3) can bind the central domain of p190RhoGAP, one of RHOA's most abundant GAPs. This interaction increases the GAP activity of p190 towards RHOA resulting in a decrease of RHOA active form and thus, an inhibition of stress fiber formation [28]. As a regulatory mechanism, the RHOA effector ROCK1 can phosphorylate p190RhoGAP, which decreases p190RhoGAP binding to RND1, so preventing the inhibitory effect of RND1 on RHOA [29].

The regulation of actin cytoskeleton by RND1 could also involve RND1 partners. RND1 can bind Syx [30], which activates RHOA. In the same way as for RND3 [30], binding of RND1 to Syx may cause Syx inhibition and in turn RHOA inhibition. A RND1 partner, Socius, was identified by the yeast two-hybrid technique using RND1 as bait [18]. The expression of Socius in a form allowing it to be addressed to the plasma membrane (Socius-CAAX) causes a loss of stress fibers [18]. Moreover, in cells co-transfected with Socius-CAAX and RND1, the expression of Socius reverses the typical RND1-dependent rounded phenotype. RND1 also interacts with the SH2 domain of Grb7 (Growth factor receptor-bound protein 7), a protein that belongs to the family of adapter proteins involved in signal transduction [31] and that stabilizes actin filaments [32]. At present, the biological effects of this interaction have not been explored. We could consider that by interacting with Grb7, RND1 may inhibit it and prevent it from activating actin stress filaments.

\subsection{Formation of Nerve Connections}

Cell polarity is essential for neuronal development and is related to changes in the actin cytoskeleton [33]. The growth cone is a structure rich in filamentous actin (actin F), located at the end of the growing axon, which connects the axon to the target neuron. A network of microtubules allows the expansion of the growth cone. The neurites-filopodia and lamellipodia-that emanate from the growth cone explore the environment in all directions. The growth cones express receptors for guide molecules and, depending on the signals received, alternate between elongation and retraction of the filopodia and lamellipodia. Rho proteins, including RND1, participate in the formation of nerve connections. 


\subsubsection{Interaction with Plexins}

RND1 can interact with different types of plexins, which are receptors for the guide molecules semaphorins. Binding of semaphorin 3A (Sema3A) ligand to neuropilin 1 (NRP1)/plexin A1 complex induces growth cone collapse. The interaction of RND1 with plexin A1 also induces the growth cone collapse even in the absence of Sema3A or NRP1 co-receptor [34] (Figure 4A). The effect of RND1 is related to the stimulation of the GTPase activity of plexin A1, which is responsible for a decrease in R-Ras activity [35]. The interaction of RND1 with plexin A1 can be inhibited by RHOD, which binds to the same binding site as RND1 [34].

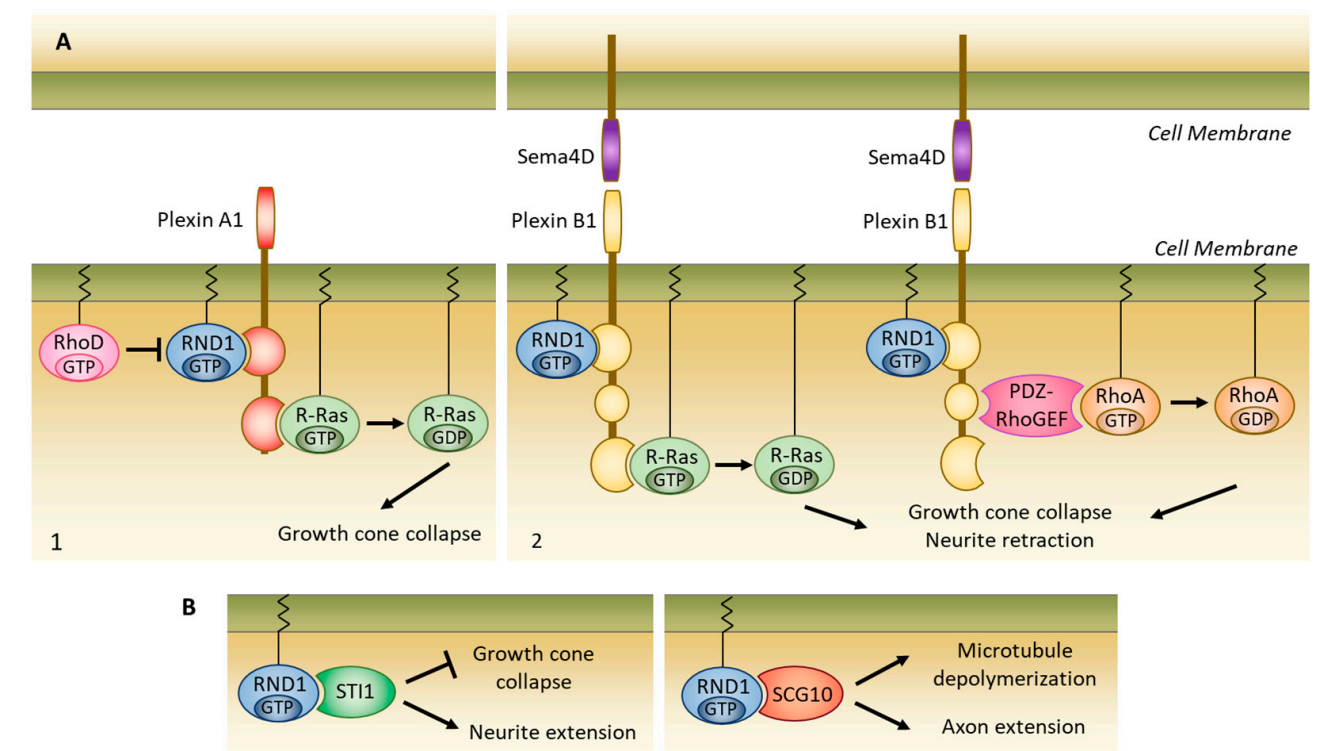

Figure 4. RND1 is involved in the formation of nerve connections. (A) Plexin dependent mechanisms. 1: The interaction of RND1 with plexin A1 stimulates its R-Ras GTPase activity, leading to the growth cone collapse. This effect occurs even in the absence of a semaphorin signal. This interaction can be inhibited by RhoD, which binds the plexin to the same binding site as RND1. 2: After stimulation by semaphorin 4D (Sema4D), the interaction of RND1 with plexin B1 stimulates its R-Ras GTPase activity and its binding with PDZ-RhoGEF, resulting in the inhibition of R-Ras and the activation of RhoA, respectively. These mechanisms both contribute to growth cone collapse and neurite retraction. (B) Plexin independent mechanisms. The interaction of RND1 with STI1 inhibits growth cone collapse inhibition induced by the RND1-Plexin A1 association and increases neurite extension. Binding of RND1 with SCG10 induces microtubule depolymerization and axon extension.

In Cos-7 cells, co-expression of RND1 and plexin B1 causes cell contraction after stimulation of plexin B1 by its ligand, semaphorin 4D (Sema4D). This effect depends on two independent mechanisms (Figure 4A). The first is linked to the increase of RHOA activity. Indeed, the binding of RND1 to plexin B1 induces the interaction of PDZ-RhoGEF to plexin B1 and its PDZ-RhoGEF activation. Consequently, PDZ-RhoGEF activation increases the activation of RHOA [36]. Similarly to plexin A1, the second mechanism depends on the inhibition of R-Ras activity. RND1 induces the binding of plexin B1 with R-Ras in its GTP-linked active form. After stimulation with Sema4D, the GAP domain of plexin B1 stimulates the GTPase activity of R-Ras and, therefore, inhibits R-Ras activation [35,37]. In Cos-7 cells, co-expression of RND1 and plexins B2 or B3 also induces cell contraction after Sema4D stimulation [38].

\subsubsection{Interaction with Other Partners}

RND1 also regulates neuronal polarity by plexin-independent mechanisms. (i) In pheochromocytoma PC-12 cells, depletion of RND1 with siRNA suppresses fibroblast growth factor (FGF)-induced neurite extension [39]. The effect of RND1 on neurite extension is linked both to its binding to the FRS2 $\beta$ 
protein (FGFR substrate $2 \beta$ ) and to its inhibitory function on RHOA [40]. (ii) RND1 can interact with STI1 (Stress-Inducible Protein), a co-chaperone protein that associates with HSP70/HSP90 [41]. This interaction inhibits the growth cone collapse induced by RND1-Plexin A1 interaction in Cos-7 cells and increases neurite extension in PC-12 cells (Figure 4B). (iii) RND1 binds SCG10 (Superior Cervical Ganglion 10), a protein that destabilizes neuronal microtubules in the growth cone and that is essential for axon extension (Figure 4B) [42]. This binding enhances the effects of SCG10 on microtubule depolymerization and induces axon extension in rat hippocampal neurons.

Depending on the type of effector that RND1 connects, RND1 activates or decreases neurite extension and induces or inhibits the growth cone collapse.

\subsubsection{Role in Embryonic Development}

Depletion of RND1 with morpholino antisense oligonucleotide (MO) in four-cell stage Xenopus embryos (into the equatorial zone) induces aberrant gastrulation movements, i.e., the leading endo-mesordermal cells fail to crawl under the ectoderm [43] (Figure 5). As a consequence, at high concentrations of RND1 MO, embryos fail to gastrulate and sometimes die. At lower concentrations of RND1 MO, the migration of endo-mesordermal cells is delayed, resulting in bent embryos. In addition to the intrinsic effect of RND1 on morphogenesis, RND1 participates in morphogenesis via its interaction with FLRT3 transmembrane protein (Fibronectin Leucine Rich Transmembrane 3) and with the netrin receptor, Unc5B $[43,44]$. During development, the interaction between RND1 and FLRT3 inhibits cell adhesion $[14,43]$ by decreasing the level of C-cadherin present at the plasma membrane through internalization of C-cadherin in the cytoplasm [43] (Figure 5). The effect of the interaction with Unc5B on the internalization of C-cadherin has not yet been explored.

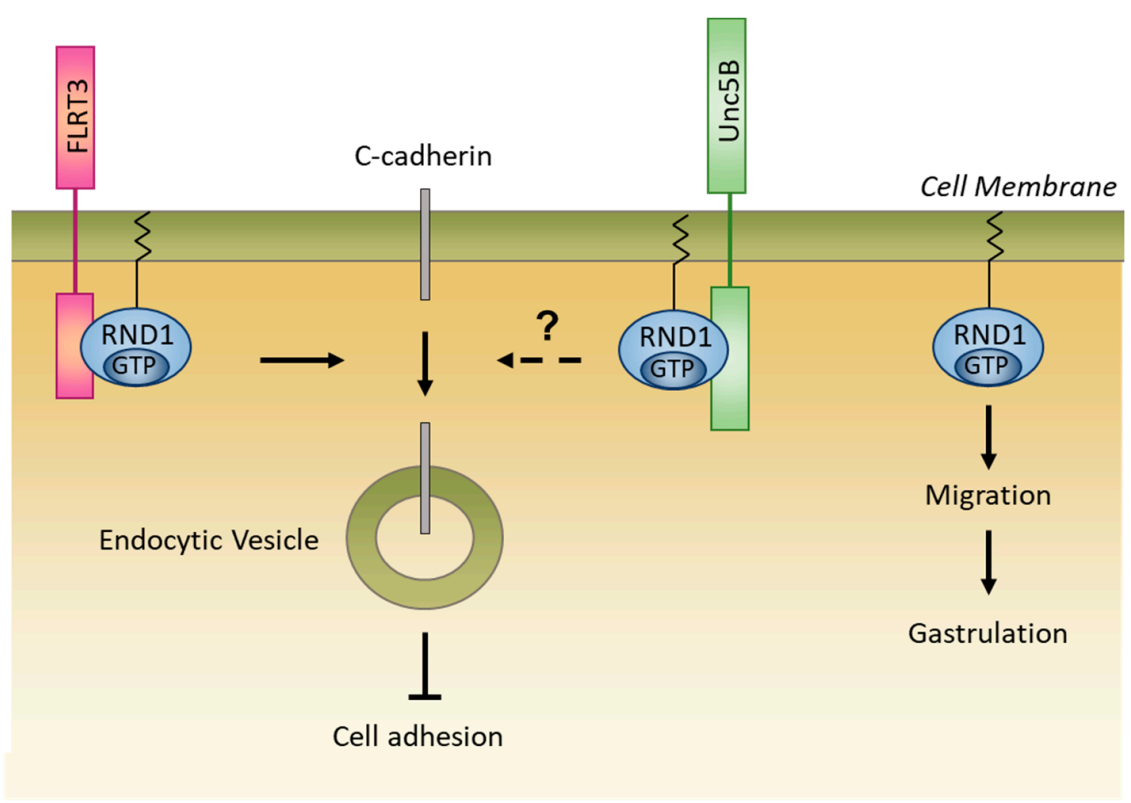

Figure 5. RND1 is involved in adhesion and migration during embryogenesis. In Xenopus embryos, RND1 can bind both the FLRT3 transmembrane protein and the netrin receptor, Unc5B. The association between RND1 and FLRT3 decreases the level of C-cadherin present on the cell surface through internalization of $\mathrm{C}$-cadherin into endocytic vesicles in the cytoplasm, resulting in cell adhesion inhibition. The effect of the interaction with Unc5B on the internalization of C-cadherin has not yet been studied. RND1 also allows endo-mesodermal cells to migrate during embryogenesis, which leads to gastrulation.

\subsubsection{Role in Angiogenesis}

RND1 appears to limit angiogenesis. Depletion of RND1 with siRNA in endothelial cells leads to an increase in VEGF-mediated endothelial migration and in the formation of neo-vessels (Figure 6) [22]. 
It has been proposed that in endothelial cells, VEGF induces the expression of RND1, which restrains the activity of RHOA and thus limits RHOA positive effects on angiogenesis [22].

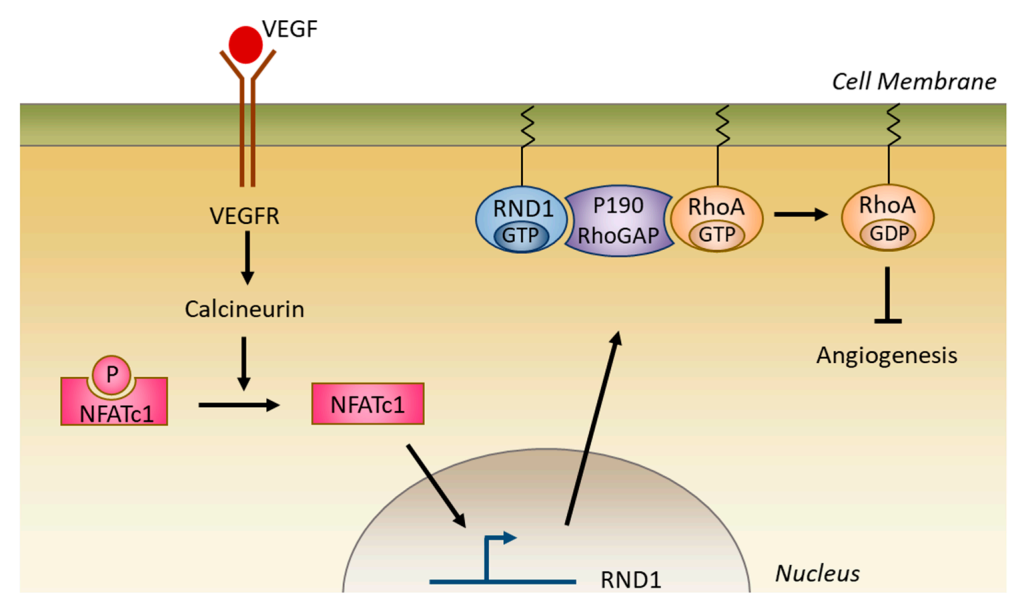

Figure 6. RND1 limits angiogenesis. Vascular endothelial growth factor (VEGF) activates calcineurin-NFATc1 signaling axis. Nuclear localized NFATc1 binds to the RND1 promoter and stimulates its transcription. The increase of RND1 decreases RHOA activation resulting in the inhibition of angiogenesis.

\section{RND1 Expression in Cancers}

\section{RND1 Expression is Altered in Cancers}

As other Rho GTPases [2], the expression of RND1 transcripts is altered in cancers. RND1 is down-regulated in the most aggressive subtypes of breast cancers (estrogen receptor negative, triple negative, and basal) [10], in hepatocellular carcinoma [45,46] and in high grade glioma [11,47]. Its expression is also lower in the advanced stages (grade III/IV) than in the early stages (grade I/II) of hepatocellular carcinoma [45] and glioma [11]. By contrast, $R N D 1$ transcripts are up-regulated in low grades of breast tumors [48], in gastric cancer cell lines [49], and in esophageal squamous cell carcinoma [50].

The low expression of RND1 in tumors was first described as being due to genetic and epigenetic mechanisms. The 12q12-q13 region where RND1 gene is located is deleted in several cancers, such as pancreas cancer [51], adenoid cystic carcinoma [52], and breast cancer [10]. In adenoid cystic carcinoma [52] and in breast cancer [10], the deletion of RND1 gene concerns only one of the two alleles. In several tumors, it has been reported that methylation of RND1 promoter and histone deacetylation induce the repression of RND1 gene transcription [10,46,53,54] (Figure 3). Moreover, in breast cancers, the Polycomb Repressor Complex 2 is involved in the inhibition of RND1 gene expression [10]. Another mechanism responsible for the low expression of RND1 in tumors is the inhibition of its transcription through the deregulation of transcription factors (Figure 3). In human breast cancers, the Oct4 transcription factor is increased compared to normal breast tissues [55] and is over-expressed in metastatic breast tumors compared to primary breast tumors [56]. Oct4 binds to the promoter of RND1 on two sites (-844 and $-1271 \mathrm{bp}$ ) and this binding inhibits RND1 transcription in the human cancer MDA-MB231 cell line [57]. More recently, long non-coding RNA (lncRNA) have been involved in the inhibition of RND1 expression (Figure 3). The lncRNA AGAP2-AS1 has been identified as a repressor of RND1 [58,59]. Inhibition of AGAP2-AS1 expression with siRNA increases RND1 mRNA in non-small lung cancer H1975 cells and gastric cancer BGC823 cells. High expression of AGAP2-AS1 in non-small cell lung cancers and gastric cancers is associated with tumor progression. These data raise the possibility that RND1 may have an anti-tumor function in these cancers.

Regarding the induction of RND1 expression in cancers, there are fewer data in the literature. Due to hypomethylation of RND1 gene, RND1 is overexpressed in gastric cell lines [49]. However, the consequences of this increase on oncogenesis are not known yet. 
Analysis of the genomic database in the cbioportal website (http:/www.cbioportal.org) reveals that several mutations in the RND1 open reading frame exist in human tumors (Figure 2 and Table 1). The majority of mutations are missense mutations (124 mutations). Sixteen truncating mutations and two fusion proteins have been discovered (Table 1). Unlike $R A C 1$ and $R H O A$ gene mutations, which occur preferentially in the G1 guanosine nucleotide binding site and the switch I and II domains [2], RND1 mutations spread over almost the entire gene sequence (Figure 2). The impact on RND1 function of four missense mutations discovered in breast tumors has been studied. Unlike wild type RND1, G70R, E98D, and F180C mutants are not able to induce a growth inhibitory activity, show an aberrant localization in the cytoplasm, and lose their ability to bind to plexin B1 [10]. The M185V RND1 mutant behaves similarly to the wild type in terms of subcellular localization and interaction with plexin B1. The impact of other RND1 mutations on its function and tumor initiation and progression remains to be determined.

Table 1. Mutations in the RND1 gene.

\begin{tabular}{|c|c|c|c|}
\hline Mutation Type & Cancer Type & Mutation Type & Cancer Type \\
\hline Missense & & Missense & \\
\hline R5G & Renal Clear Cell C & M137I & Cutaneous Melanoma \\
\hline V11A & Stomach A. Diffuse Type Stomach AdenoC & Q142H & Adrenocortical C \\
\hline $\mathrm{V} 11 \mathrm{M}$ & Prostate Neuroendocrine C. Prostate AdenoC & E150D & $\begin{array}{c}\text { High-Grade Serous Ovarian Cancer. Serous } \\
\text { Ovarian Cancer }\end{array}$ \\
\hline $\mathrm{C} 14 \mathrm{~F}$ & $\begin{array}{l}\text { Renal Clear Cell C with sarcomatoid features. High-Grade } \\
\text { Serous Ovarian C. Serous Ovarian C }\end{array}$ & A154T & Uterine Endometrioid C \\
\hline C14S & Bladder Urothelial C & A156S & Uterine Endometrioid C \\
\hline V17I & Bladder Urothelial C & G160S & Cutaneous Melanoma \\
\hline G20V & Cutaneous Melanoma & E162D & Intestinal Type Stomach AdenoC \\
\hline T45I & Hepatocellular C. Cutaneous Melanoma & L165P & Colorectal AdenoC \\
\hline $\mathrm{V} 46 \mathrm{M}$ & Colorectal AdenoC. Uterine Endometrioid C & E166K & Cutaneous melanoma \\
\hline E48K & Cutaneous Melanoma & G167D & Astrocytoma \\
\hline E57G & Acute Myeloid Leukemia & A169V & Cutaneous melanoma \\
\hline E57K & Lung AdenoC & F180C & Breast C \\
\hline E58K & Bladder Urothelial C & R181W & Cutaneous melanoma \\
\hline E62V & Lung Squamous Cell C & S184F & Melanoma \\
\hline G70R & Breast $\mathrm{C}$ & S184T & Renal Clear Cell C \\
\hline P72S & Cutaneous Squamous Cell C & S184Y & Uterine Endometrioid C \\
\hline $\mathrm{D} 75 \mathrm{H}$ & Breast Invasive Ductal C & M185V & Breast $\mathrm{C}$ \\
\hline $\mathrm{D} 75 \mathrm{~N}$ & Colorectal AdenoC. Cutaneous Melanoma & P191S & Colorectal AdenoC \\
\hline S85L & Uterine Endometrioid C & Q196H & Hepatocellular C \\
\hline $\mathrm{D} 86 \mathrm{~N}$ & Cutaneous Melanoma & L203F & Lung Squamous Cell C \\
\hline A87V & Uterine Endometrioid C & $\mathrm{R} 213 \mathrm{H}$ & Uterine Carcinosarcoma. Colorectal AdenoC \\
\hline $\mathrm{R} 96 \mathrm{H}$ & $\begin{array}{c}\text { Prostate Neuroendocrine C. Uterine Endometrioid C. } \\
\text { Colon AdenoC }\end{array}$ & S214F & Uterine Endometrioid C \\
\hline E98D & Breast $\mathrm{C}$ & $\mathrm{I} 217 \mathrm{M}$ & $\begin{array}{l}\text { Invasive Breast C. Breast Mixed Ductal and } \\
\text { Lobular C. Breast Invasive Ductal C } \\
\end{array}$ \\
\hline $\mathrm{D} 101 \mathrm{~N}$ & Bladder Urothelial C & Truncating & \\
\hline A103T & Stomach AdenoC. Uterine Endometrioid C & $\mathrm{A} 6 \mathrm{Pfs} * 28$ & Mucinous AdenoC of the colon and rectum \\
\hline K106Q & Uterine Endometrioid C & $\mathrm{Q} 8 \mathrm{Pfs} * 8$ & Renal Clear Cell C. Stomach AdenoC \\
\hline W107G & Cutaneous Melanoma & X70_splice & Pancreatic AdenoC \\
\hline R108K & Cutaneous Melanoma & X107_splice & Esophagogastric AdenoC \\
\hline R108M & Cutaneous Melanoma & E162* & Uterine Endometrioid C \\
\hline E110K & Cutaneous Melanoma & Y164* & Lung AdenoC \\
\hline P116S & Bladder Urothelial C & S168* & Bladder Urothelial C \\
\hline S117N & Glioblastoma Multiforme & $\mathrm{R} 201$ * & Colon AdenoC \\
\hline T118A & Colorectal AdenoC & $\mathrm{R} 206^{*}$ & Uterine Serous/Papillary Serous C \\
\hline I123F & Pancreatic AdenoC & & \\
\hline K126N & Cervical Squamous Cell C & Fusion protein & \\
\hline R130Q & $\begin{array}{l}\text { Uterine Endometrioid C. Colorectal AdenoC. Mucinous } \\
\text { AdenoC of the colon and rectum }\end{array}$ & MLL2-RND1 & Esophageal AdenoC \\
\hline D132G & Mucinous AdenoC of the colon and rectum & DDX23-RND1 & Hepatocellular C \\
\hline
\end{tabular}




\section{RND1 in Oncogenesis}

The alterations of RND1 expression in tumors and an in silico analysis that identified RND1 as a tumor suppressor gene [60] suggest a potential role of RND1 in oncogenesis. In breast tissue, the loss of RND1 induces tumorigenesis in mammary epithelial cells [10]. On the contrary, the re-introduction of RND1 gene in mammary tumor cells slows down the tumor growth [10]. The loss of RND1 in mammary epithelial cells also contributes to tumor progression via (i) the induction of epithelial to mesenchymal transition (EMT), (ii) the induction of proliferation, and (iii) the ability to migrate and metastasize. These tumor progression effects induced by RND1 depletion are mediated through the activation of the Ras and MAPK pathways [10].

The role of RND1 in EMT has been extended to hepatocellular carcinoma cells, in which the depletion of RND1 also causes EMT, this time via the activation of RHOA [46]. In glioblastoma initiating cells, the expression of RND1 is inversely correlated with mesenchymal gene expression, such as TWIST1, SNAI1, and SNAI2 [47], suggesting that RND1 blocks the mesenchymal phenotype.

Concerning the role of RND1 in tumor cell proliferation and migration, the results seem to be dependent on the tumor type. The depletion of RND1 induces hepatocellular carcinoma proliferation [45], whereas it decreases esophageal squamous cell carcinoma proliferation [50]. The silencing of RND1 increases the in vitro migration and invasion of glioblastoma initiating cells [47] and hepatocellular carcinoma cells $[45,46]$. In hepatocellular carcinoma cells, the increase of invasion induced by RND1 depletion is mediated by the activation of RHOA [46]. In contrast to these data, the silencing of RND1 in esophageal carcinoma cells decreases their in vitro migration and metastasis capacity [50]. All these proliferation and migration data show that a dysregulation of the amount of RND1 (either overexpression or decreased expression) in cancer cells increases the proliferation and migratory capacity of these cells. In fact, as described in the previous section, RND1 is down-regulated in hepatocellular carcinoma, in the most aggressive subtypes of breast cancers and in glioblastoma patients, whereas it is over-expressed in esophageal squamous cell carcinoma, which could explain the contradictive effects of its variation on cell behavior.

\section{RND1 In Vital Prognosis}

RND1 has been described as a prognosis factor of survival for patients with an estrogen receptor negative breast cancer [10], with hepatocellular carcinoma [45,46] or glioblastoma [47]. In these tumors, a weak expression of RND1 is correlated with a bad prognosis. In glioblastoma, we identified an $R N D 1^{\text {low }}$ signature of six genes (ITGA5, COL3A1, COL5A1, MET, COL1A2, LAMC1), upregulated in glioblastoma patients with low RND1, that predicts the overall survival of glioblastoma patients. Moreover, by multivariate statistical analysis that tests its independence from other known prognostic factors, we determined that in glioblastoma the $R N D 1^{\text {low }}$ signature is an independent prognostic factor [47]. This $R N D 1^{\text {low }}$ signature may be helpful in clinical practice to predict the survival of glioblastoma patients. This signature might also lead to clinical application to optimize the treatment of glioblastoma through the targeting of genes involved in this signature.

\section{RND1 in Response to Anticancer Agents}

\section{RND1 Expression and Its Role in Response to Anticancer Agents}

Screening approaches on chips have shown that RND1 expression is increased in response to anticancer agents. Co-treatment of chronic myeloid leukemia cells with imatinib, a tyrosine kinase inhibitor of Bcr-Abl protein, and the antioxidant agent amifostine, increases RND1 mRNA levels after $48 \mathrm{~h} \mathrm{[61].} \mathrm{RND1} \mathrm{mRNA} \mathrm{is} \mathrm{also} \mathrm{induced} \mathrm{in} \mathrm{human} \mathrm{lymphocytes} 15 \mathrm{~min}$ after ionizing irradiation [62]. Using a RT-qPCR screen of Rho GTPase expression in response to the topoisomerase I inhibitor camptothecin, we identified RND1 as a Rho GTPase gene, which is rapidly induced in the osteosarcoma U2OS cell line [53]. The poly (ADP-ribose) polymerase (PARP-1) activity is responsible for the induction of RND1 transcription after treatment with camptothecin (Figure 3). This rapid induction of RND1 
is also found in several non-tumorigenic cells, such as NIH3T3 fibroblasts, and in other tumor cells, such as U87 glioblastoma cells. In contrast, the expression of RND2 and RND3, the two RND1 homologs, is not induced after a short treatment with camptothecin [53].

There are currently few data on the effect of RND1 expression on cell sensitivity to anticancer agents. In hepatocellular carcinoma, RND1 depletion with siRNA induces the resistance of hepatocellular carcinoma cells to cisplatin, a water-soluble platinum complex [45], whereas RND1 re-expression induced by cell treatment with an inducer of promoter hypomethylation and an histone deacetylase inhibitor increases the cellular sensitivity to the Raf inhibitor, sorafenib [46]. The induction of RND1 protects osteosarcoma cells against camptothecin, likely by inhibiting apoptosis [53]. From these data, we can conclude that the effect of RND1 on cell sensitivity appears to depend on the cell type or the drug used.

In order to study whether RND1 expression could be associated with the sensitivity of cancer cells to anticancer therapies (either cytotoxic or targeted agents), we analyzed the potential correlation between RND1 expression and the cellular response to 20 anticancer agents with the CCLE database (https://portals.broadinstitute.org/ccle). Among the 23 analyzed tumor localizations, the hematological and lymphoid tissue is the tumor type for which the sensitivity to anticancer agents is the most dependent on the RND1 mRNA levels (Table 2). Figure 7 shows that in these hematological and lymphoid tumors, the lower RND1 is expressed, the more sensitive the tumor is to inhibitors of growth factor receptors i.e., IGFR1 (AEW541), EGFR (erlotinib), c-met (PF2341066), multiple receptor tyrosine kinase (TKI258), the MAPK pathway (AZD6244, PD-0325901, RAF265), tyrosine kinases i.e., Abl and Alk (nilotinib, TAE684) and $\gamma$ secretase (L-685458). To determine whether this correlation is specific to RND1 or could be generalized to RND3, we also analyzed the potential correlation between RND3 expression and the cellular response to 20 anticancer agents in hematological and lymphoid tumor cells. In these tumor cells, the only significant correlation observed between RND3 expression and anticancer agent susceptibility is for PD-0332991, a cdk 4/6 inhibitor (Table 3), showing that the response profile to these agents is specific to a particular RND member. With regards to other tumor localizations, it should be noted that the inverse correlation between sensitivity to a $\gamma$ secretase inhibitor and RND1 levels identified in the hematological and lymphoid tumor cells, is also observed in large intestine, ovary, and skin tumor cells (Table 2). Interestingly, the inverse correlation between the sensitivity to the EGFR inhibitor erlotinib and the amount of RND1 transcripts is also found in large intestine tumor cells. In addition, the more RND1 is expressed, the more sensitive kidney and lung tumor cells are to the EGFR inhibitor lapatinib. When EGFR is activated, it activates the MAPK pathway. The sensitivity to MAPK inhibitors and the levels of RND1 is also found in the lung tumor cells (Table 2). These data suggest a role for RND1 expression in the sensitivity of tumors to EGFR signaling pathway inhibitors. Moreover, according to tumor cell type, positive and negative correlation between the levels of RND1, and the sensitivity to EGFR inhibitors can be found. This necessitates the molecular mechanisms linking RND1 to cancer cell sensitivity. 
Table 2. Correlations between RND1 expression and sensitivity to anticancer agents in several tumor cells.

\begin{tabular}{|c|c|c|c|c|c|c|c|c|c|c|c|c|c|c|c|}
\hline $\begin{array}{l}\text { Anticancer } \\
\text { Agents }\end{array}$ & Drug Target & $\begin{array}{c}\text { Auton } \\
\text { Ganglia }\end{array}$ & Bone & Breast & Endom & Hematopoietic & Kidney & $\begin{array}{c}\text { Large } \\
\text { Intestine }\end{array}$ & Liver & Lung & Ovary & Pancreas & Pleura & Skin & $\begin{array}{c}\text { Aero } \\
\text { Digestive }\end{array}$ \\
\hline 17AAG & Hsp90 & ns & ns & ns & ns & ns & ns & ns & ns & ns & ns & ns & ns & ns & ns \\
\hline AEW541 & IGFR1 & ns & $\begin{array}{r}0.6273, \\
p=0.039 \\
\end{array}$ & ns & ns & $\begin{array}{l}-0.3068, \\
p=0.009\end{array}$ & ns & ns & ns & $\begin{array}{c}0.2936, \\
p=0.005 \\
\end{array}$ & ns & ns & ns & ns & ns \\
\hline AZD0530 & Src & ns & ns & ns & ns & ns & ns & ns & ns & ns & ns & ns & $\begin{array}{l}-0.8214, \\
p=0.023\end{array}$ & ns & ns \\
\hline AZD6244 & MEK & ns & ns & ns & ns & $\begin{array}{l}-0.4611 \\
p=10^{-4}\end{array}$ & ns & ns & ns & ns & ns & ns & ns & ns & ns \\
\hline Erlotinib & EGFR & ns & ns & ns & ns & $\begin{array}{l}-0.3332, \\
p=0.005\end{array}$ & ns & $\begin{array}{l}-0.4383 \\
p=0.036\end{array}$ & ns & ns & ns & ns & ns & ns & ns \\
\hline Irinotecan & Topo I & ns & ns & ns & ns & ns & ns & ns & ns & $\mathrm{ns}$ & ns & ns & ns & ns & ns \\
\hline L-685458 & $\gamma$ secretase & ns & ns & ns & ns & $\begin{array}{l}-0.3147, \\
p=0.008\end{array}$ & ns & $\begin{array}{l}-0.4230 \\
p=0.049\end{array}$ & ns & ns & $\begin{array}{l}-0.4225, \\
p=0.025\end{array}$ & ns & ns & $\begin{array}{l}-0.3957 \\
p=0.013\end{array}$ & ns \\
\hline LBW242 & IAP & ns & ns & ns & ns & ns & ns & ns & ns & ns & ns & ns & ns & ns & $\mathrm{ns}$ \\
\hline Lapatinib & EGFR & ns & ns & ns & ns & ns & $\begin{array}{c}0.800 \\
p=0.010\end{array}$ & ns & ns & $\begin{array}{c}0.2649 \\
p=0.011\end{array}$ & ns & ns & ns & ns & ns \\
\hline Nilotinib & $\mathrm{Abl}$ & ns & $0.7, p=0.036$ & ns & ns & $\begin{array}{l}-0.2816 \\
p=0.019\end{array}$ & ns & ns & $\begin{array}{c}0.7088, \\
p=0.007\end{array}$ & ns & ns & ns & ns & ns & ns \\
\hline Nutlin-3 & p53-mdm2 & ns & ns & ns & ns & ns & ns & ns & ns & ns & ns & ns & ns & ns & $\mathrm{ns}$ \\
\hline PD-0325901 & MEK & ns & ns & ns & ns & $\begin{array}{r}-0.4359, \\
p=0.0001\end{array}$ & ns & ns & ns & $\begin{array}{c}0.2592 \\
p=0.013\end{array}$ & ns & ns & ns & ns & ns \\
\hline PD-0332991 & $\operatorname{cdk} 4 / 6$ & $\begin{array}{l}-0.8214, \\
p=0.023\end{array}$ & ns & ns & $\begin{array}{c}0.6571, \\
p=0.008\end{array}$ & ns & ns & ns & ns & ns & ns & ns & ns & ns & ns \\
\hline PF2341066 & c-met & ns & ns & ns & ns & $\begin{array}{l}-0.2580 \\
p=0.030\end{array}$ & ns & ns & ns & ns & ns & ns & ns & ns & ns \\
\hline PHA-665752 & c-met & ns & ns & ns & ns & ns & ns & ns & ns & ns & ns & ns & ns & ns & ns \\
\hline PLX4720 & B-Raf ${ }^{\mathrm{V} 600 \mathrm{E}}$ & ns & ns & ns & ns & ns & ns & ns & ns & ns & ns & $\begin{array}{l}-0.4286 \\
p=0.026\end{array}$ & ns & ns & ns \\
\hline Paclitaxel & Microtubules & ns & ns & ns & ns & ns & ns & ns & ns & ns & ns & ns & ns & ns & $\begin{array}{c}0.9286 \\
p=0.003 \\
\end{array}$ \\
\hline Panobinostat & HDAC & ns & ns & ns & ns & ns & ns & $\begin{array}{l}-0.4200 \\
p=0.046\end{array}$ & ns & ns & ns & ns & $\begin{array}{c}0.9286, \\
p=0.003\end{array}$ & ns & ns \\
\hline RAF265 & B-Raf & ns & ns & ns & ns & $\begin{array}{l}-0.3737, \\
p=0.002\end{array}$ & ns & ns & ns & ns & ns & ns & ns & ns & ns \\
\hline Sorafenib & $\begin{array}{l}\text { Tyrosine } \\
\text { kinase }\end{array}$ & ns & ns & ns & ns & ns & ns & ns & ns & ns & ns & ns & ns & ns & ns \\
\hline TAE684 & Alk & ns & ns & $\begin{array}{l}-0.4084 \\
p=0.028\end{array}$ & ns & $\begin{array}{l}-0.2847, \\
p=0.016\end{array}$ & ns & ns & ns & ns & ns & ns & ns & ns & ns \\
\hline
\end{tabular}


Table 2. Cont

\begin{tabular}{|c|c|c|c|c|c|c|c|c|c|c|c|c|c|c|c|}
\hline $\begin{array}{l}\text { Anticancer } \\
\text { Agents }\end{array}$ & Drug Target & $\begin{array}{l}\text { Auton } \\
\text { Ganglia }\end{array}$ & Bone & Breast & Endom & Hematopoietic & Kidney & $\begin{array}{c}\text { Large } \\
\text { Intestine }\end{array}$ & Liver & Lung & Ovary & Pancreas & Pleura & Skin & $\begin{array}{c}\text { Aero } \\
\text { Digestive }\end{array}$ \\
\hline TKI258 & $\begin{array}{c}\text { Receptor } \\
\text { tyrosine } \\
\text { kinase }\end{array}$ & ns & ns & ns & ns & $\begin{array}{l}-0.2764 \\
p=0.020\end{array}$ & $\begin{array}{l}-0.8333, \\
p=0.005\end{array}$ & ns & ns & ns & ns & $\begin{array}{l}-0.3996, \\
p=0.035\end{array}$ & ns & ns & ns \\
\hline Topotecan & Topo I & ns & ns & ns & ns & ns & ns & ns & ns & ns & ns & ns & ns & ns & $\mathrm{ns}$ \\
\hline ZD-6474 & VEGFR & ns & ns & ns & ns & ns & ns & ns & ns & ns & ns & ns & ns & ns & ns \\
\hline
\end{tabular}

Using the CCLE database, correlation between quantitative data were determined by Spearman's rank correlation coefficient (the cellular sensitivity to anticancerous agents was analyzed statistically significant. All statistical analyses were performed using STATA 12.0 software. Twenty three tumor localizations were studied. Those for which no correlation has been found do not appear in the table: they correspond to the biliary tract, the central nervous system, the esophagus, the prostate, the salivary gland, the soft tissue, the stomach thyroid, and the urinary tract. Auton: autonomic, endom: endometrium, hematopoietic: hematopoietic and lymphoid tissue, aerodigestive: upper aerodigestive tract. "TopoI" is the abbreviation for Topoisomerase I. ns=not significant. The first value is the correlation coefficient; the second one is the Spearman's $p$-value. 

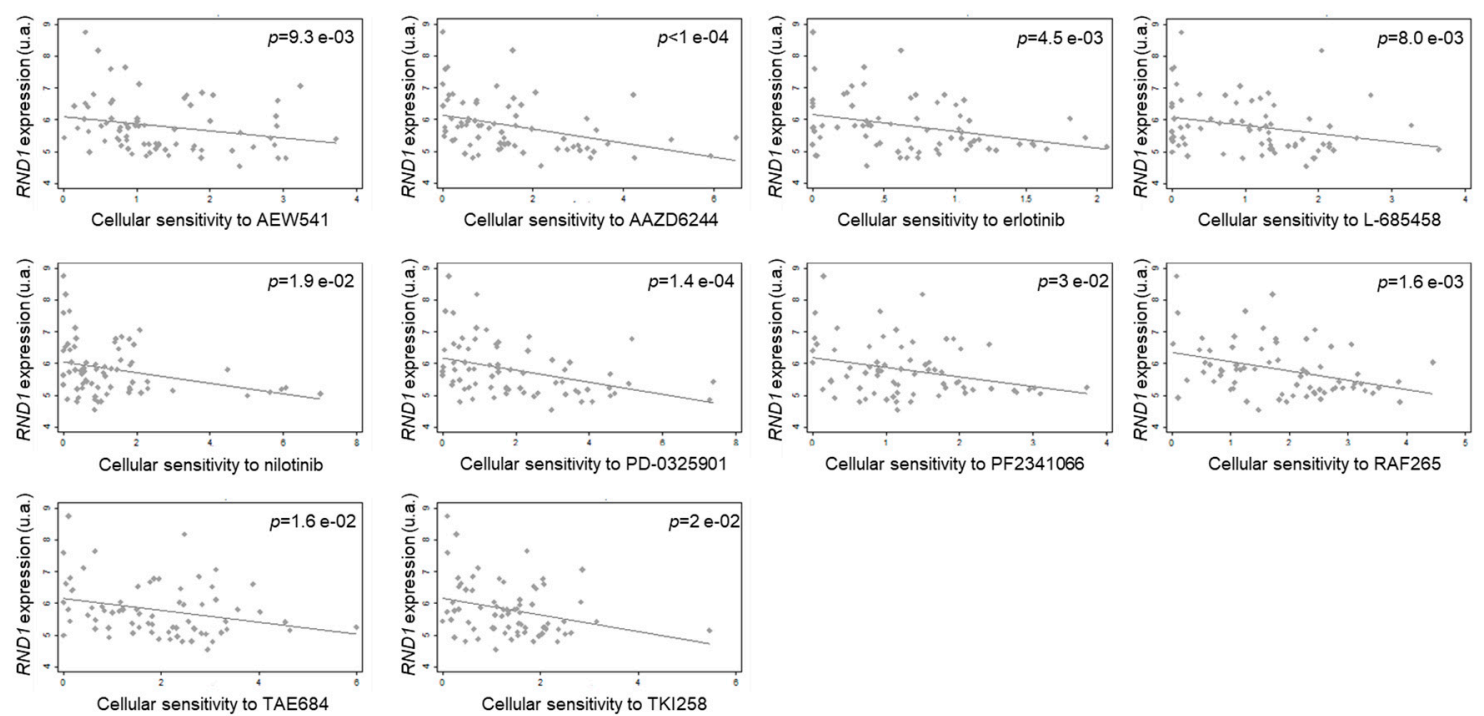

Figure 7. Correlation between RND1 expression and sensitivity to anticancer agents in hematological and lymphoid tumor cells. Using the CCLE database, correlations between quantitative data were determined as in Table 2 . Two-sided $p$-values of less than 0.05 were considered statistically significant. All statistical analyses were performed using STATA 12.0 software.

Table 3. Correlations between RND3 expression and sensitivity to anticancerous agents in hematological and lymphoid tumor cells.

\begin{tabular}{ccc}
\hline Anticancerous Agents & Correlation Coefficient & $p$ Value \\
\hline 17-AAG & 0.1237 & 0.3040 \\
AEW541 & 0.1882 & 0.1160 \\
AZD0530 & 0.0841 & 0.4855 \\
AZD6244 & 0.0554 & 0.6464 \\
Erlotinib & -0.1070 & 0.3743 \\
Irinotecan & 0.0493 & 0.7311 \\
L-685458 & -0.0054 & 0.9648 \\
LBW242 & 0.0479 & 0.6917 \\
Lapatinib & 0.1342 & 0.2646 \\
Nilotinib & 0.1233 & 0.3130 \\
Nutlin-3 & 0.0628 & 0.6026 \\
PD-0325901 & 0.0478 & 0.6923 \\
PD-0332991 & $0.2655 *$ & 0.0275 \\
PF2341066 & 0.1118 & 0.3532 \\
PHA-665752 & 0.1113 & 0.3553 \\
PLX4720 & 0.0846 & 0.4831 \\
Paclitaxel & 0.0959 & 0.4262 \\
Panobinostat & -0.0325 & 0.7879 \\
RAF265 & -0.0446 & 0.7159 \\
Sorafenib & 0.0902 & 0.4544 \\
TAE684 & 0.1848 & 0.1229 \\
TKI258 & -0.0148 & 0.9026 \\
Topotecan & 0.0772 & 0.5224 \\
ZD-6474 & 0.0897 & 0.4571 \\
\hline
\end{tabular}

Correlation between quantitative data was assessed as in Table 2. Two-sided $p$-values of less than 0.05 were considered statistically significant. All statistical analyses were performed using STATA 12.0 software. *: significant.

\section{Conclusions}

In several tumors (triple negative breast cancer, hepatocellular carcinoma, and glioblastoma), RND1 presents the features of a tumor suppressor gene i.e.,: (i) in breast tissue, its loss induces mammary tumorigenesis [10], (ii) its re-expression in tumor cells causes the cell to lose two cancerous properties (invasion/metastasis, proliferation) [10,45-47], (iii) its expression is down-regulated in tumors and is inversely correlated with the stage of the tumors [11,45]; and (iv) a weak expression of RND1 is correlated with a bad prognosis for the patients [10,45-47]. However, data from esophageal 
squamous cell carcinoma refute the idea that RND1 would be a universal tumor suppressor gene [50]. Apart from its role in oncogenesis, RND1 is a gene induced by anticancer agents and is involved at least in the cellular resistance to cisplatin [45], to sorafenib [46] and camptothecin [53]. The in silico data of sensitivity to anticancer agents, which must be verified with patient samples, offers new research perspectives on RND1 in response to anticancer agents.

In clinical practice, the RND1 rate may be useful to predict patient response to standard therapy. This has already been strongly suggested for breast tumors, hepatocarcinoma, and glioblastoma [10,45-47], but could be studied and extended to other tumors. In addition, for patients who do not respond to standard therapy, the RND1 rate in tumor biopsies could be helpful in selecting the most appropriate targeted therapy for each patient. In particular, for patients with hematopoietic and lymphoid tumors, determining the levels of RND1 in tumor tissues would help to evaluate their response to inhibitors of growth factor receptors (IGFR1, EGFR, c-met and multiple receptor tyrosine kinase), MAPK pathway, tyrosine kinases (Abl and Alk), and $\gamma$ secretase.

Author Contributions: Each author agrees to be personally accountable for the author's own contributions and for ensuring that questions related to the accuracy or integrity of any part of the work, even ones in which the author was not personally involved, are appropriately investigated, resolved, and documented in the literature.

Funding: Laetitia Mouly was supported by Region Midi-Pyrenees/INSERM.

Acknowledgments: We thank Isabelle Lazoie-Mazenc for her clear explanations on RHO structure.

Conflicts of Interest: ECJM has served as advisory board member for Merck-Serono. The other cited authors, which all concurred with the present article, declare no potential conflicts of interest.

$\begin{array}{ll}\text { Abbreviations } & \\ \text { EMT } & \text { Epithelial to mesenchymal transition } \\ \text { FGF } & \text { Fibroblast growth factor } \\ \text { FRS2 } \beta & \text { FGFR substrate } 2 \beta \\ \text { FLRT3 } & \text { Fibronectin Leucine Rich Transmembrane 3 } \\ \text { GAP } & \text { GTPase-activating protein } \\ \text { GDI } & \text { GDP-dissociation inhibitors } \\ \text { GEF } & \text { Guanine nucleotide Exchange Factor } \\ \text { Grb7 } & \text { Growth factor receptor-bound protein } 7 \\ \text { lncRNA } & \text { Long non-coding RNA } \\ \text { MO } & \text { Morpholino antisense oligonucleotide } \\ \text { NFATc1 } & \text { Nuclear Factor of Activated T Cells } \\ \text { NRP1 } & \text { Neuropilin 1 } \\ \text { PARP-1 } & \text { Poly (ADP-ribose) polymerase } \\ \text { SCG10 } & \text { Superior Cervical Ganglion 10 } \\ \text { Sema } & \text { Semaphorin } \\ \text { STI1 } & \text { Stress-Inducible Protein } \\ \text { TGF- } \beta & \text { Transforming growth factor beta } \\ \text { VEGF } & \text { Vascular endothelial growth factor }\end{array}$

\section{References}

1. Heasman, S.J.; Ridley, A.J. Mammalian Rho GTPases: New insights into their functions from in vivo studies. Nat. Rev. Mol. Cell Biol. 2008, 9, 690-701. [CrossRef] [PubMed]

2. Bustelo, X.R. RHO GTPases in cancer: Known facts, open questions, and therapeutic challenges. Biochem. Soc. Trans. 2018, 46, 741-760. [CrossRef] [PubMed]

3. Nobes, C.D.; Lauritzen, I.; Mattei, M.-G.; Paris, S.; Hall, A.; Chardin, P. A New Member of the Rho Family, Rnd1, Promotes Disassembly of Actin Filament Structures and Loss of Cell Adhesion. J. Cell Boil. 1998, 141, 187-197. [CrossRef] [PubMed]

4. Shutes, A.; Berzat, A.C.; Cox, A.D.; Der, C.J. Atypical Mechanism of Regulation of the Wrch-1 Rho Family Small GTPase. Curr. Boil. 2004, 14, 2052-2056. [CrossRef] [PubMed] 
5. Oinuma, I.; Kawada, K.; Tsukagoshi, K.; Negishi, M. Rnd1 and Rnd3 targeting to lipid raft is required for p190 RhoGAP activation. Mol. Biol. Cell 2012, 23, 1593-1604. [CrossRef] [PubMed]

6. Riou, P.; Villalonga, P.; Ridley, A.J. Rnd proteins: Multifunctional regulators of the cytoskeleton and cell cycle progression. BioEssays 2010, 32, 986-992. [CrossRef]

7. Jaffe, A.B.; Hall, A. RHO GTPASES: Biochemistry and Biology. Annu. Rev. Cell Dev. Boil. 2005, 21, $247-269$. [CrossRef] [PubMed]

8. Ridley, A.J. Rho GTPase signalling in cell migration. Curr. Opin. Cell Biol. 2015, 36, 103-112. [CrossRef]

9. Zandvakili, I.; Lin, Y.; Morris, J.C.; Zheng, Y. Rho GTPases: Anti- or pro-neoplastic targets? Oncogene 2017, 36, 3213-3222. [CrossRef]

10. Okada, T.; Sinha, S.; Esposito, I.; Schiavon, G.; Lopez-Lago, M.A.; Su, W.; Pratilas, C.A.; Abele, C.; Hernandez, J.M.; Ohara, M.; et al. The Rho GTPase Rnd1 suppresses mammary tumorigenesis and EMT by restraining Ras-MAPK signalling. Nat. Cell Biol. 2015, 17, 81-94. [CrossRef]

11. Clarke, K.; Daubon, T.; Turan, N.; Soulet, F.; Mohd Zahari, M.; Ryan, K.R.; Durant, S.; He, S.; Herbert, J.; Ankers, J.; et al. Inference of Low and High-Grade Glioma Gene Regulatory Networks Delineates the Role of Rnd3 in Establishing Multiple Hallmarks of Cancer. PLoS Genet. 2015, 11, e1005325. [CrossRef] [PubMed]

12. Grise, F.; Sena, S.; Bidaud-Meynard, A.; Baud, J.; Hiriart, J.-B.; Makki, K.; Dugot-Senant, N.; Staedel, C.; Bioulac-Sage, P.; Zucman-Rossi, J.; et al. Rnd3/RhoE Is down-regulated in hepatocellular carcinoma and controls cellular invasion. Hepatology 2012, 55, 1766-1775. [CrossRef] [PubMed]

13. Paysan, L.; Piquet, L.; Saltel, F.; Moreau, V. Rnd3 in Cancer: A Review of the Evidence for Tumor Promoter or Suppressor. Mol. Cancer Res. 2016, 14, 1033-1044. [CrossRef] [PubMed]

14. Wünnenberg-Stapleton, K.; Blitz, I.L.; Hashimoto, C.; Cho, K.W. Involvement of the small GTPases XRhoA and XRnd1 in cell adhesion and head formation in early Xenopus development. Development 1999, 126, 5339-5351. [PubMed]

15. Ishikawa, Y.; Katoh, H.; Negishi, M. A Role of Rnd1 GTPase in Dendritic Spine Formation in Hippocampal Neurons. J. Neurosci. 2003, 23, 11065-11072. [CrossRef] [PubMed]

16. Kim, Y.-S.; Hori, M.; Yasuda, K.; Ozaki, H. Differences in the gestational pattern of mRNA expression of the Rnd family in rat and human myometria. Comp. Biochem. Physiol. Part A Mol. Integr. Physiol. 2005, 142, 410-415. [CrossRef]

17. Kim, Y.S.; Kim, B.; Karaki, H.; Hori, M.; Ozaki, H. Up-regulation of Rnd1 during pregnancy serves as a negative-feedback control for $\mathrm{Ca}^{2+}$ sensitization of contractile elements in rat myometrium. Biochem. Biophys. Res. Commun. 2003, 311, 972-978. [CrossRef]

18. Katoh, H.; Harada, A.; Mori, K.; Negishi, M. Socius Is a Novel Rnd GTPase-Interacting Protein Involved in Disassembly of Actin Stress Fibers. Mol. Cell. Biol. 2002, 22, 2952-2964. [CrossRef]

19. Roberts, P.J.; Mitin, N.; Keller, P.J.; Chenette, E.J.; Madigan, J.P.; Currin, R.O.; Cox, A.D.; Wilson, O.; Kirschmeier, P.; Der, C.J. Rho Family GTPase modification and dependence on CAAX motif-signaled posttranslational modification. J. Biol. Chem. 2008, 283, 25150-25163. [CrossRef]

20. Riou, P.; Kjær, S.; Garg, R.; Purkiss, A.; George, R.; Cain, R.J.; Bineva, G.; Reymond, N.; McColl, B.; Thompson, A.J.; et al. 14-3-3 Proteins Interact with a Hybrid Prenyl-Phosphorylation Motif to Inhibit G Proteins. Cell 2013, 153, 1164. [CrossRef]

21. Song, R.; Gu, J.; Liu, X.; Zhu, J.; Wang, Q.; Gao, Q.; Zhang, J.; Cheng, L.; Tong, X.; Qi, X.; et al. Inhibition of osteoclast bone resorption activity through osteoprotegerin-induced damage of the sealing zone. Int. J. Mol. Med. 2014, 34, 856-862. [CrossRef] [PubMed]

22. Suehiro, J.-I.; Kanki, Y.; Makihara, C.; Schadler, K.; Miura, M.; Manabe, Y.; Aburatani, H.; Kodama, T.; Minami, T. Genome-wide Approaches Reveal Functional Vascular Endothelial Growth Factor (VEGF)-inducible Nuclear Factor of Activated T Cells (NFAT) c1 Binding to Angiogenesis-related Genes in the Endothelium. J. Biol. Chem. 2014, 289, 29044-29059. [CrossRef] [PubMed]

23. Loirand, G.; Cario-Toumaniantz, C.; Chardin, P.; Pacaud, P. The Rho-related protein Rnd1 inhibits Ca ${ }^{2+}$ sensitization of rat smooth muscle. J. Physiol. 1999, 516, 825-834. [CrossRef] [PubMed]

24. Monastyrskaya, K.; Sanchez-Freire, V.; Gheinani, A.H.; Klumpp, D.J.; Babiychuk, E.B.; Draeger, A.; Burkhard, F.C. miR-199a-5p Regulates Urothelial Permeability and May Play a Role in Bladder Pain Syndrome. Am. J. Pathol. 2013, 182, 431-448. [CrossRef] [PubMed]

25. Zhang, C.; Lu, J.; Liu, B.; Cui, Q.; Wang, Y. Primate-specific miR-603 is implicated in the risk and pathogenesis of Alzheimer's disease. Aging (Albany N. Y.) 2016, 8, 272-290. [CrossRef] [PubMed] 
26. Hodge, R.G.; Ridley, A.J. Regulating Rho GTPases and their regulators. Nat. Rev. Mol. Cell Biol. 2016, 17, 496-510. [CrossRef] [PubMed]

27. Goh, L.L.; Manser, E. The GTPase-deficient Rnd Proteins Are Stabilized by Their Effectors. J. Biol. Chem. 2012, 287, 31311-31320. [CrossRef] [PubMed]

28. Wennerberg, K.; Forget, M.-A.; Ellerbroek, S.M.; Arthur, W.T.; Burridge, K.; Settleman, J.; Der, C.J.; Hansen, S.H. Rnd Proteins Function as RhoA Antagonists by Activating p190 RhoGAP. Curr. Biol. 2003, 13, 1106-1115. [CrossRef]

29. Mori, K.; Amano, M.; Takefuji, M.; Kato, K.; Morita, Y.; Nishioka, T.; Matsuura, Y.; Murohara, T.; Kaibuchi, K. Rho-kinase contributes to sustained RhoA activation through phosphorylation of p190A RhoGAP. J. Biol. Chem. 2009, 284, 5067-5076. [CrossRef]

30. Goh, L.L.; Manser, E. The RhoA GEF Syx Is a Target of Rnd3 and Regulated via a Raf1-Like Ubiquitin-Related Domain. PLoS ONE 2010, 5, e12409. [CrossRef] [PubMed]

31. Vayssière, B.; Zalcman, G.; Mahé, Y.; Mirey, G.; Ligensa, T.; Weidner, K.; Chardin, P.; Camonis, J. Interaction of the Grb7 adapter protein with Rnd1, a new member of the Rho family. FEBS Lett. 2000, 467, 91-96. [CrossRef]

32. García-Palmero, I.; Villalobo, A. Deletion of the calmodulin-binding domain of Grb7 impairs cell attachment to the extracellular matrix and migration. Biochem. Biophys. Res. Commun. 2013, 436, 271-277. [CrossRef] [PubMed]

33. Prokop, A.; Beaven, R.; Qu, Y.; Sánchez-Soriano, N. Using fly genetics to dissect the cytoskeletal machinery of neurons during axonal growth and maintenance. J. Cell Sci. 2013, 126, 2331-2341. [CrossRef] [PubMed]

34. Zanata, S.M.; Hovatta, I.; Rohm, B.; Püschel, A.W. Antagonistic Effects of Rnd1 and RhoD GTPases Regulate Receptor Activity in Semaphorin 3A-Induced Cytoskeletal Collapse. J. Neurosci. 2002, 22, 471-477. [CrossRef] [PubMed]

35. Oinuma, I. The Semaphorin 4D Receptor Plexin-B1 Is a GTPase Activating Protein for R-Ras. Science 2004, 305, 862-865. [CrossRef] [PubMed]

36. Oinuma, I.; Katoh, H.; Harada, A.; Negishi, M. Direct Interaction of Rnd1 with Plexin-B1 Regulates PDZ-RhoGEF-mediated Rho Activation by Plexin-B1 and Induces Cell Contraction in COS-7 Cells. J. Biol. Chem. 2003, 278, 25671-25677. [CrossRef] [PubMed]

37. Oinuma, I.; Katoh, H.; Negishi, M. Molecular Dissection of the Semaphorin 4D Receptor Plexin-B1-Stimulated R-Ras GTPase-Activating Protein Activity and Neurite Remodeling in Hippocampal Neurons. J. Neurosci. 2004, 24, 11473-11480. [CrossRef] [PubMed]

38. Yukawa, K.; Tanaka, T.; Yoshida, K.; Takeuchi, N.; Ito, T.; Takamatsu, H.; Kikutani, H.; Kumanogoh, A. Sema4A induces cell morphological changes through B-type plexin-mediated signaling. Int. J. Mol. Med. 2010, 25, 225-230. [CrossRef] [PubMed]

39. Harada, A.; Katoh, H.; Negishi, M. Direct interaction of Rnd1 with FRS2 beta regulates Rnd1-induced down-regulation of RhoA activity and is involved in fibroblast growth factor-induced neurite outgrowth in PC12 cells. J. Biol. Chem. 2005, 280, 18418-18424. [CrossRef]

40. Chardin, P. Function and regulation of Rnd proteins. Nat. Rev. Mol. Cell Biol. 2006, 7, 54-62. [CrossRef]

41. De Souza, L.E.R.; Costa, M.D.M.; Bilek, E.S.; Lopes, M.H.; Martins, V.R.; Püschel, A.W.; Mercadante, A.F.; Nakao, L.S.; Zanata, S.M. STI1 antagonizes cytoskeleton collapse mediated by small GTPase Rnd1 and regulates neurite growth. Exp. Cell Res. 2014, 324, 84-91. [CrossRef] [PubMed]

42. Li, Y.-H.; Ghavampour, S.; Bondallaz, P.; Will, L.; Grenningloh, G.; Püschel, A.W. Rnd1 regulates axon extension by enhancing the microtubule destabilizing activity of SCG10. J. Biol. Chem. 2009, 284, 16060.

43. Ogata, S.; Morokuma, J.; Hayata, T.; Kolle, G.; Niehrs, C.; Ueno, N.; Cho, K.W. TGF-beta signaling-mediated morphogenesis: Modulation of cell adhesion via cadherin endocytosis. Genes Dev. 2007, 21, 1817-1831. [CrossRef] [PubMed]

44. Karaulanov, E.; Böttcher, R.T.; Stannek, P.; Wu, W.; Rau, M.; Ogata, S.; Cho, K.W.Y.; Niehrs, C. Unc5B Interacts with FLRT3 and Rnd1 to Modulate Cell Adhesion in Xenopus Embryos. PLoS ONE 2009, 4, 5742. [CrossRef]

45. Komatsu, H.; Iguchi, T.; Masuda, T.; Hirata, H.; Ueda, M.; Kidogami, S.; Ogawa, Y.; Sato, K.; Hu, Q.; Nambara, S.; et al. Attenuated RND1 Expression Confers Malignant Phenotype and Predicts Poor Prognosis in Hepatocellular Carcinoma. Ann. Surg. Oncol. 2017, 24, 850-859. [CrossRef]

46. Qin, C.-D.; Ma, D.-N.; Zhang, S.-Z.; Zhang, N.; Ren, Z.-G.; Zhu, X.-D.; Jia, Q.-A.; Chai, Z.-T.; Wang, C.-H.; Sun, H.-C.; et al. The Rho GTPase Rnd1 inhibits epithelial-mesenchymal transition in hepatocellular carcinoma and is a favorable anti-metastasis target. Cell Death Dis. 2018, 9, 486. [CrossRef] 
47. Boyrie, S.; Delmas, C.; Lemarié, A.; Lubrano, V.; Dahan, P.; Malric, L.; Luis, J.; Gilhodes, J.; Tosolini, M.; Mouly, L.; et al. RND1 regulates migration of human glioblastoma stem-like cells according to their anatomical localization and defines a prognostic signature in glioblastoma. Oncotarget 2018, 9, 33788-33803. [CrossRef]

48. Jiang, W.G.; Watkins, G.; Lane, J.; Cunnick, G.H.; Douglas-Jones, A.; Mokbel, K.; Mansel, R.E. Prognostic value of rho GTPases and rho guanine nucleotide dissociation inhibitors in human breast cancers. Clin. Cancer Res. 2003, 9, 6432-6440.

49. Nishigaki, M.; Aoyagi, K.; Danjoh, I.; Fukaya, M.; Yanagihara, K.; Sakamoto, H.; Yoshida, T.; Sasaki, H. Discovery of aberrant expression of R-RAS by cancer-linked DNA hypomethylation in gastric cancer using microarrays. Cancer Res. 2005, 65, 2115-2124. [CrossRef]

50. Xiang, G.; Yi, Y.; Weiwei, H.; Weiming, W. RND1 is up-regulated in esophageal squamous cell carcinoma and promotes the growth and migration of cancer cells. Tumour Biol. 2016, 37, 773-779. [CrossRef]

51. Aguirre, A.J.; Brennan, C.; Bailey, G.; Sinha, R.; Feng, B.; Leo, C.; Zhang, Y.; Zhang, J.; Gans, J.D.; Bardeesy, N.; et al. High-resolution characterization of the pancreatic adenocarcinoma genome. Proc. Natl. Acad. Sci. USA 2004, 101, 9067-9072. [CrossRef] [PubMed]

52. Rutherford, S.; Hampton, G.M.; Frierson, H.F.; Moskaluk, C.A. Mapping of candidate tumor suppressor genes on chromosome 12 in adenoid cystic carcinoma. Lab. Investig. 2005, 85, 1076-1085. [CrossRef] [PubMed]

53. Mouly, L.; Mamouni, K.; Gence, R.; Cristini, A.; Cherier, J.; Castinel, A.; Legrand, M.; Favre, G.; Sordet, O.; Monferran, S. PARP-1-dependent RND1 transcription induced by topoisomerase I cleavage complexes confers cellular resistance to camptothecin. Cell Death Dis. 2018, 9, 931. [CrossRef] [PubMed]

54. Nishigaki, R.; Osaki, M.; Hiratsuka, M.; Toda, T.; Murakami, K.; Jeang, K.-T.; Ito, H.; Inoue, T.; Oshimura, M. Proteomic identification of differentially-expressed genes in human gastric carcinomas. Proteomics 2005, 5, 3205-3213. [CrossRef] [PubMed]

55. Soheili, S.; Asadi, M.H.; Farsinejad, A. Distinctive expression pattern of OCT4 variants in different types of breast cancer. Cancer Biomark. 2017, 18, 69-76. [CrossRef] [PubMed]

56. Kar, S.; Patra, S.K. Overexpression of OCT4 induced by modulation of histone marks plays crucial role in breast cancer progression. Gene 2018, 643, 35-45. [CrossRef]

57. Shen, L.; Qin, K.; Wang, D.; Zhang, Y.; Bai, N.; Yang, S.; Luo, Y.; Xiang, R.; Tan, X. Overexpression of Oct4 suppresses the metastatic potential of breast cancer cells via Rnd1 downregulation. Biochim. Biophys. Acta (BBA) Mol. Basis Dis. 2014, 1842, 2087-2095. [CrossRef]

58. Li, W.; Sun, M.; Zang, C.; Ma, P.; He, J.; Zhang, M.; Huang, Z.; Ding, Y.; Shu, Y. Upregulated long non-coding RNA AGAP2-AS1 represses LATS2 and KLF2 expression through interacting with EZH2 and LSD1 in non-small-cell lung cancer cells. Cell Death Dis. 2016, 7, e2225. [CrossRef]

59. Qi, F.; Liu, X.; Wu, H.; Yu, X.; Wei, C.; Huang, X.; Ji, G.; Nie, F.; Wang, K. Long noncoding AGAP2-AS1 is activated by SP1 and promotes cell proliferation and invasion in gastric cancer. J. Hematol. Oncol. 2017, 10, 11. [CrossRef]

60. Chen, L.; Zhang, Y.-H.; Zhang, Z.; Huang, T.; Cai, Y.-D. Inferring Novel Tumor Suppressor Genes with a Protein-Protein Interaction Network and Network Diffusion Algorithms. Mol. Ther. Methods Clin. Dev. 2018, 10, 57-67. [CrossRef]

61. Bianchini, M.; Martinelli, G.; Renzulli, M.; Gonzalez Cid, M.; Larripa, I. cDNA microarray study to identify expression changes relevant for apoptosis in K562 cells co-treated with amifostine and imatinib. Cancer Chemother. Pharmacol. 2007, 59, 349-360. [CrossRef] [PubMed]

62. Turtoi, A.; Brown, I.; Oskamp, D.; Schneeweiss, F.H.A. Early gene expression in human lymphocytes after gamma-irradiation-A genetic pattern with potential for biodosimetry. Int. J. Radiat. Biol. 2008, 84, 375-387. [CrossRef] [PubMed]

(C) 2019 by the authors. Licensee MDPI, Basel, Switzerland. This article is an open access article distributed under the terms and conditions of the Creative Commons Attribution (CC BY) license (http://creativecommons.org/licenses/by/4.0/). 